Article

\title{
Sustainable Development Strategy of Chinese Animation Industry
}

\author{
Kuo-Kuang Fan and Ting-Ting Feng *
}

Graduate School of Design, National Yunlin University of Science and Technology, Douliou 64002, Taiwan; fankk@gemail.yuntech.edu.tw

* Correspondence: fengtingting23@gmail.com; Tel.: +886-0903-783-706

check for updates

Citation: Fan, K.-K.; Feng, T.-T. Sustainable Development Strategy of Chinese Animation Industry. Sustainability 2021, 13, 7235. https://doi.org/10.3390/su13137235

Academic Editors: Charo Sadaba,

Mónica Herrero and

Patricia SanMiguel

Received: 13 May 2021

Accepted: 25 June 2021

Published: 28 June 2021

Publisher's Note: MDPI stays neutral with regard to jurisdictional claims in published maps and institutional affiliations.

Copyright: (C) 2021 by the authors. Licensee MDPI, Basel, Switzerland. This article is an open access article distributed under the terms and conditions of the Creative Commons Attribution (CC BY) license (https:/ / creativecommons.org/licenses/by/ $4.0 /)$.

\begin{abstract}
The animation industry is a crucial part of cultural and creative industries and has formed a huge consumer market all over the world and even become a pillar industry in developed countries. However, in China, the animation industry is still in its infancy, and its development is relatively backward. The main reason is that there is no sustainable development model in the industry. Thus, how to carry out sustainable development has become an important research topic for the Chinese animation industry. This study probed into the challenges and problems faced by China's animation industry, and based on Porter's Diamond Model, analyzed the current situation of China's animation industry from six aspects: production factors, demand conditions, industrial chain, enterprise strategy, cultural factors, and government policies, clarifies the key direction for industrial development, and puts forward relatively comprehensive reference strategies to promote the formation of a sustainable development model for the animation industry. The research shows that the sustainable development of the animation industry must be completed by integrating resources within the industry, improving the chain, upgrading the enterprises, technological innovations, cultural embedding, external personnel training, government support, legal protection, and other aspects.
\end{abstract}

Keywords: animation industry; sustainable development; cultural factors

\section{Introduction}

With the global developments of science and technology and the continuous progress of new media technology, the animation industry has become a core industry of the economy in the 21st century. The products of animated art entering the economic field refer to production, making, distribution, and broadcasting, with creativity as the core, animation as the form of expression, and television, film, and network new media as the main means of communication, as well as the production and sales of derivative products, such as clothing, stationery, and games, as developed based on the animated images [1]. As one of the five pillar industries of cultural and creative industries, animation can create new growth points in the national economy and effectively enhance the soft power of national culture. The animation industry is characterized by: (1) Based on animation images; (2) Ideological; (3) Has a diversified and complex industrial system; (4) Uses mass media as a means of communication [2]. Animation is a medium; it does not equal television or movies and is not simply an artistic style [3], but is a product of the combination of information technology and art. Moreover, it is also an important industry featuring cultural creativity, high technology, and intensive intellectual labor and is hailed as "smokeless heavy industry" in the global economy. In the United States, the major animation companies headed by Disney have the most perfect animation industry chain in the world, and the animation industry is one of the most profitable and fastest-growing pillar industries in the United States, while in Japan, the animation industry has become the second pillar industry.

John Hawkins once said, "Creative industries can create the value of USD 22 billion every day" [4], which shows the important role of cultural and creative industries in people's lives. The goods and services provided by creative industries have simple cultural 
value or entertainment value, as well as economic value [5]. With the development of the economy and the improvement of people's living standards, people's cultural needs are also expanding day by day. As a kind of cultural and creative industry, the animation industry has become a new force to promote economic development. Asia, the third market of creative and media in the world, and China is one of the fast-growing markets in this region [6]. According to the relevant statistics of the Ministry of Culture, the total output value of China's animation industry in 2012 was close to RMB 76 billion; in 2017, the total output value of China's animation industry was RMB 153.6 billion, and by 2020, China's animation industry can achieve the industrial output value scale target of RMB 250 billion in the 13th Five-Year Plan [7] (Figure 1).

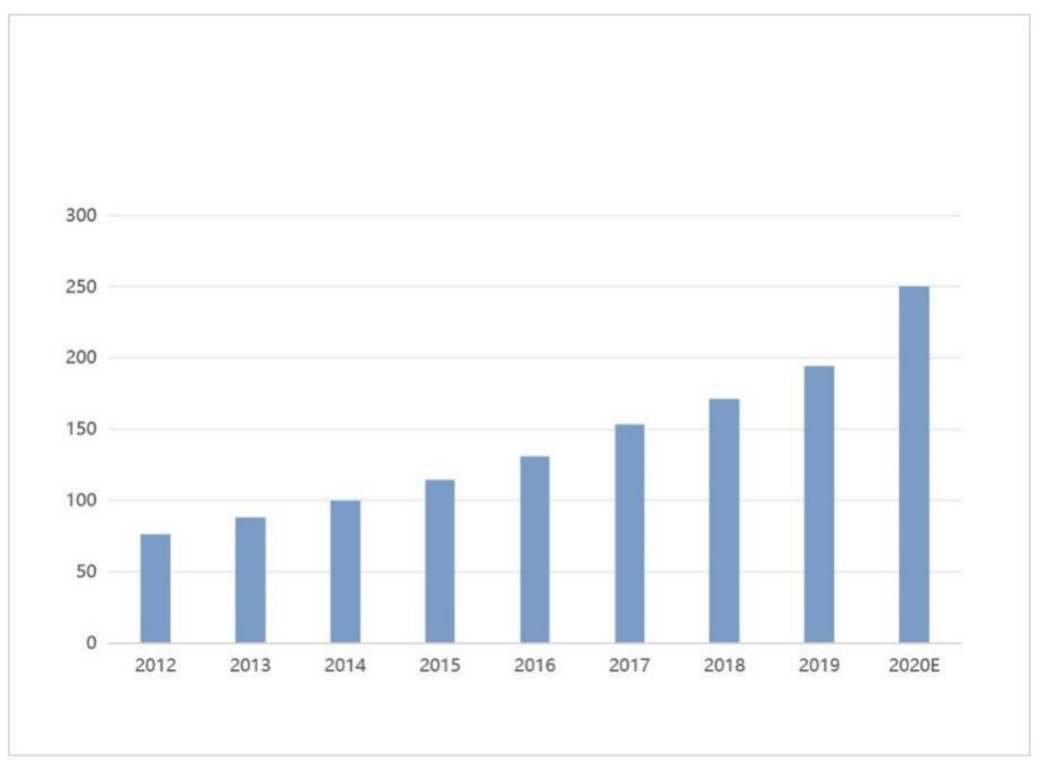

Figure 1. Total Output Value of China's Animation Industry in Recent Decade (RMB billion) [7].

The animation industry has a great market value. Although it is a rising industry in China, it is still in the stage of development and exploration, and compared with the mature industrial model abroad, there is still a big gap. The imperfect industrial model leads to the failure of China's animation industry to form a sustainable development model, and thus, has been unable to gain advantages in international competition. Currently, the animation market in China is dominated by American and Japanese works, while domestic animation works only appeal to a small number of audiences whose ages tend to be lower and lower [8]. As a result of the inadequate development model, the overall development of the animation industry in China is slow and lacks driving power, making it hard to cope with the situation where its share in the domestic market has been eroded. In early 2008, scholars proposed that the animation industry in China should seek sustainable development [9]. However, to date, a sustainable development model has yet to take shape. Hence, finding a way to promote the sustainable development of the animation industry has become a major subject of current studies of the animation industry. As the world's second-largest economy, China has a broad market, as well as more opportunities for the domestic animation industry. Proceeding from the status quo of the animation industry in China, this study probes into the difficulties and challenges faced by the industry and attempts to determine a way to solve the issues accordingly. This study aims at exploring the strategies for the animation industry in China to ensure sustainable development. With the guidance of the Michael Porter Diamond Model, this study provides valuable references from various aspects, such as infusing more cultural messages, perfecting relevant policies, and improving the industrial chain of animation, in order that China's animation market and industrial chain model can be improved, competitiveness particular 
to China's animation industry can be built, and the sustainable development of this industry can be achieved.

This study first conducted a literature review on the status quo of China's animation industry to gain an objective understanding of its latest developments. Then according to the six perspectives of the Michael Porter Diamond Model, this study examined the sustainable development strategies in order to improve the research system of animation, enrich the current theories on the development of the animation industry, and provide a new way of thinking to create macro-policies for the industry, and thus, facilitate the sustainable development of China's animation industry. Meanwhile, as an essential component of cultural and creative industries and an important carrier for the expression of Chinese culture, the animation industry plays a role in the inheritance and diffuseness of traditional culture. The sustainable development and enhancement of the core competitiveness of this industry will play an effective role in diffusing and promote Chinese cultural ethos within China, even in the world, and the soft power of culture will be enhanced accordingly.

\section{Literature Review}

\subsection{Literature Review of China's Animation Industry}

The development of China's animation industry has gone through five stages $[10,11]$ (Table 1); however, it was not until the 21st century that the government successively issued relevant policies to support the animation industry [12]. In April 2004, the National Radio and Television Administration issued Several Opinions on the Development of China's Film and Television Animation Industry, which transformed "animation" into the "animation industry" for the first time [13]. The Several Opinions on Promoting the Development of China's Animation Industry, as issued in 2006, and the Nine Measures to Promote the Development of Domestic Animation Films, as issued in 2013, clearly planned to set up special funds to increase financial support for domestic animated films and identified fifteen animation industry bases and four animation teaching and research bases [14,15]. Among them, the Nine Measures also proposed holding an annual Sino-foreign animation film cooperation forum and a domestic animation film creation forum and organizing domestic animation film enterprises and products to participate in film festivals with international influence [15].

Currently, the animation industry is defined as an industry supported by arts, science, and technology, manifested in the form of cartoons and animated film, based on the creation of animated direct products, and extending to developing the derivatives of brand image, and thus, has a large copyright value chain [16]. At the same time, as a typical kind of intellectual and artistic product, animation products are influenced by the historical and social environment of the time [17]. Animation plays a role in the inheritance and diffusion of the cultural ideology of the day. Therefore, the sustainable development and the cultural brand building of the animation industry are both closely related to the enhancement of a country's soft power and one of the symbols of a country or a nation's culture [18].

The animation industry has development value in three aspects: culture, economy, and arts [2]; thus, it is a combination of artistry and commerciality. However, earlier Chinese animation products only highlighted their artistry while forsaking their commerciality as commercial products. Thus, the animation industry in China failed to form a timely industrial model, making it an increasingly weak player against the backdrop of marketization. Hence the development of the animation industry must start with marketization and improvement of the industrial chain [19].

In light of the experience of countries with well-developed animation industries, Some of the important changes in the Japanese animation industry are concerned with the influence of public cultural policies [20]. The popularity of Japanese animation mainly lies in the originality supported by Japanese native culture [21]. In Japan, there are great market demands, government-provided guidance, perfect public utilities, high-quality human resources, and research institutes where the internal division of labor is sophisticated [22]. In addition, public policies, financial support, and emphasis on talent education are all important factors accounting for Japan's success in the animation industry [23]. 
Japanese animation companies will outsource some labor-intensive processes, most notably In-Betweening and Colouring (IB-TP), to overseas subcontractors in China, South Korea, and Southeast Asia to achieve the highest production efficiency, and it accounts for approximately 70 percent of such processes [24]. It can be seen that the development of the animation industry lies in the reasonable arrangement, coordinated deployment, and overall planning of the industrial chain.

Table 1. The Development Course of China's Animation Industry $[10,11]$.

\begin{tabular}{|c|c|c|}
\hline Time & Stage & Features \\
\hline 1922-1945 & Germination stage & $\begin{array}{l}\text { The production level kept pace with } \\
\text { the world level at that time. The } \\
\text { manufacturing process was } \\
\text { complex, the output was low, the } \\
\text { market share was small, and the } \\
\text { sustainable circular development } \\
\text { industrial structure was not formed }\end{array}$ \\
\hline 1946-1965 & Prosperous period & $\begin{array}{l}\text { Gained rapid development and } \\
\text { realized the transformation from } \\
\text { black and white to color. Set up a } \\
\text { professional factory for } \\
\text { independent animation production } \\
\text { and created the animation style of } \\
\text { "Chinese School" by combining } \\
\text { opera, ink painting, paper cutting, } \\
\text { puppets, and other artistic forms. }\end{array}$ \\
\hline 1966-1976 & Stagnation period & $\begin{array}{l}\text { The number of works has decreased } \\
\text { sharply, and industrial } \\
\text { development has almost completely } \\
\text { stagnated. Not only has China been } \\
\text { overtaken by other countries, but it } \\
\text { has seen a talent gap, backward } \\
\text { technology, aging equipment, and } \\
\text { rigid concepts. }\end{array}$ \\
\hline
\end{tabular}

A number of animation production departments emerged and tried to use market-oriented management

1977-1998 Recovery period methods to manage the enterprises. The animation industry carried out system reform and began to have the concept of an industrial chain.
In 1922, the Wan brothers filmed China's first animated film, Uproar in the Studio, which started the journey of animation development in China.

In 1941, they produced Asia's first animated feature film, Princess Iron Fan.

The Shanghai Animation Film Studio was established in 1957 and became the first cartoon production base in China. In 1961 and 1964, the first and second episodes of The Monkey King were launched, respectively, which became the peak works in the history of Chinese animation. Both production technology and artistic attainments were at the highest level in the world at that time.

Due to social environment reasons, animation production bases have stopped production one after another, which has greatly impacted the animation industry and resulted in serious obstruction of industry's development.

As animation works were far away from their commodity attributes, they lost their economic significance.

With the reform of the economic environment, the rapid development of the national economy, the growing popularity of $\mathrm{TV}$, and higher demands for animation boosted the production of series cartoons. However, at the same time, a large number of foreign animation works entered the Chinese market, which impacted the Chinese animation industry. Although Chinese animation was developing continuously, its development speed was slow and fell behind the pace of developed countries.

The Magic Lotus Lantern, as produced in 1999, was called China's first domestic animation blockbuster. However, due to improper connections between upstream and downstream industries and the inadequate development of derivative products, the income was not high. Similarly, 2015's

Monkey King: Hero is Back and Ne Zha, the number one animation box office in Asia in 2019, was plagued by problems in derivative product development. It can be seen that China's animation industry has not formed a sustainable industrial development model at present. 
Some scholars hold the view that China's current animation industry is in desperate need of competitiveness and even used the phrase "old, weak, sick, and disabled" to describe it [25]. Inadequate market cultivation, an incomplete industrial chain, lack of talent in various links, and a defective managerial system are comparatively serious problems at present [26]. Hence, China's animation industry can draw on the experience of developed countries and improve the industrial chain step by step in order to produce original animation. It shall build the awareness of business operations and reform from three aspects: human capital, industrial cooperation, and innovative development [27]. Various measures, such as improving core competitiveness, promoting a multilevel model of development, and cultivating diversified talents for animation, are urgent measures to be taken [28].

Current studies on China's animation industry mainly focus on exploring the problems it faces and its development in a single aspect, such as policy, culture, competitiveness, and industrial chain, while the overall measures concerning the sustainable development of the animation industry are rarely investigated. Sustainable development is the major objective of China's animation industry, as well as an inevitable trend for its future development. Hence, based on the Michael Porter Diamond Model, this study proposes some comprehensive and systematic measures for inference, which are intended to provide insights into the development of the animation industry.

\subsection{Challenges and Problems Faced by China's Animation Industry}

The sustainable development of the animation industry requires a healthy and coordinated development model with content creation as the core, technological innovation as the means, culture as the driving force, and the industrial chain as the support in order that the developments of the animation industry, society, the economy, and cultural assets can constitute a circular sustainable development environment. The animation industry chain is an interrelated, inseparable, and complete operation system [29], which is divided into upstream, middle, and downstream modes. The upstream carries out creative development and production of content, the midstream carries out broadcasting and publicity, and the downstream carries out production and sales of derivatives [30,31] (Figure 2). The combination of these processes provides a complete production approach for the conception, production, development, and sales of the animation industry. Without the support of the industrial chain, the industry cannot develop healthily and continuously. If the industrial chain breaks, problems will occur within the industry. Therefore, all links must cooperate with each other to develop in a coordinated manner.

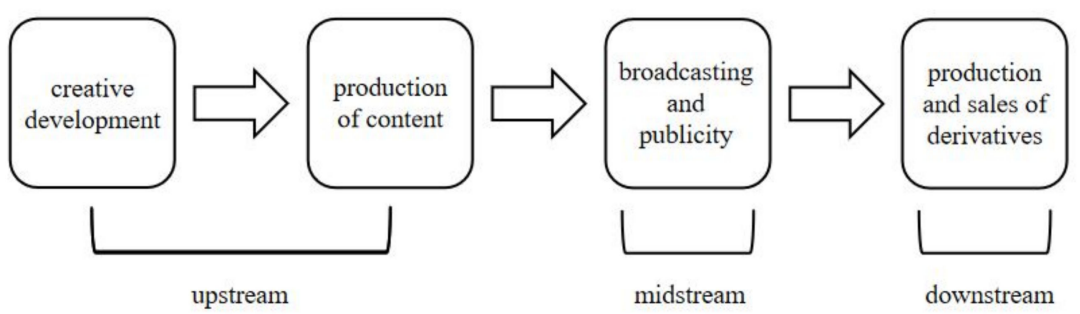

Figure 2. Animation Industry Chain $[30,31]$.

\subsubsection{Contents}

The upstream part of the animation industry is mainly the creative development and production of animation content. Contemporary Chinese animation has lost the original artistic characteristics of the Chinese school in its development process and blindly caters to secular aesthetics, thus, forming batch and large-scale assembly line production. Under such efficient replication, innovation was inevitably ignored [32], which resulted in homogenization and simplification. In the aspects of character shaping and scene design, the rendering and contrast functions of characters and scenes are ignored. With the 
introduction of foreign animation, Chinese animation has even appeared to merely imitate other countries in many aspects, leading to formulaic plots and stereotyped characters.

For a long time, Chinese audiences thought that animated films were made for children and belong only to children. Under the guidance of such a limited cognitive concept, most animation works default their target audiences to children at the beginning of their creation, which also formed the problem of the rigid positioning of ideological animation content, and animation shows to have the characteristics of puerility [8].

Meanwhile, Chinese animation has been exploring the road of nationalization, which stresses that Chinese elements should be shown as much as possible; however, no breakthrough has been made. The main problem is that Chinese animation pays too much attention to the form and fails to focus on the contents and cultural connotations, which present simple expressions, and forms a tangible and godless formal and vacant language; thus, it cannot gain recognition from audiences. Animation works should reflect the high cultural heritage and artistic accomplishment. At present, Chinese animation narrowly understands the content as concrete cultural elements and cultural props while ignoring the ideological core brought by connotation to the content. Therefore, even if the works look rich, the essence is still formalistic and lacks the most basic appeal for audiences [33].

\subsubsection{Industry-Oriented}

Compared with foreign animation industry models, there are a series of problems in Chinese animation, such as the incomplete industrial chain and unclear business model, as well as a lack of market operations, industrial operation experience, well-known IP brands, and small enterprise scale. First, in the upstream animation creation, Chinese animation creation features large investment in the early stage of animation creation, long creation cycle, and uncertain return; for example, the creation cycle of Monkey King: Hero is Back (2015) was 8 years, that of Big Fish \& Begonia (2016) was nearly 10 years, that of $\mathrm{Ne}$ Zha (2019) was 5 years, and that of Legend of Deification (2020) was 4 years. With the development of the animation industry, two animation enterprise models have gradually formed [34]. Enterprises that are good at art place too much emphasis on the artistic attributes of animation while ignoring the commercial attributes, which results in weak financial strength and leads to the slow development of enterprises, while enterprises that are good at operations lack artistic attributes. Therefore, too much focus on the commercial attribute leads to a poor artistic level. Different emphasis directions make it hard for animation works to strike a balance between artistic attributes and commercial attributes.

At present, the marketing of China's animation industry features single product positioning and single marketing channels [35], and domestic animation brands are poorly managed, which often hinders marketing due to insufficient publicity funds, thus, directly affecting the development of derivatives in the later period. In the process of formulating a marketing strategy, the product strategy is incomplete due to a lack of early preparation. In addition, there is a lack of market and consumer data. Due to a lag in market timing, it is hard to interact with consumers, which makes the target customer groups and market positioning of the works vague in the marketing stage, and the expected results cannot be achieved [36]. The lack of animation marketing methods in China leads to the low added value of products, and there are no well-known animation brands, such as Disney and DreamWorks Animation. Obviously, the industry lack templates for model development and leading enterprises that can lead the industry and occupy a high market share. Although the importance of brand development and the market value of brands have been recognized, the brand development of Chinese animation is still in the infant stage, upstream planning and production are broken from the downstream product development, and the development of derivative products has become a weak link.

The most innovative and value-added work in the animation industry occurs mainly in the early stages of production, namely the planning and pre-preproduction stages [37]. Licensing operations for the derivative products have also been a major source of revenue for animation companies [38]. In 2017, the total output value of Chinese animation was 
RMB 153.6 billion, of which the output value of the derivatives market was RMB 76.4 billion, which was about twice that of the content market, and an increase of more than RMB 30 billion, as compared with 2016. In Japan, the ratio of film and television animation income to derivatives profit is 3:7, while in the United States, it is as high as 1:9 [39]. In addition, such derivatives can also promote the works again. The development of derivatives is based on animation branding, which is an in-depth excavation of animation brand value, and a lack of animation brands will make the development of derivatives difficult. Moreover, in the process of investment and production of animation, most Chinese animation enterprises ignore the development and sales plan of derivatives at the back end of the industrial chain and spend $90 \%$ of the funds on early planning and production, while the funds for later derivatives research and development are less than $10 \%$, and sometimes there is no investment in this aspect [39]. Moreover, the protection of copyright in the Chinese market is weak, and piracy is frequently seen. Manufacturers produce pirated peripheral products without authorization, which adversely affects genuine derivatives and hinders the development of derivatives in the downstream of the industrial chain.

Compared with the complete industrial chain in foreign countries, China's animation industry has always lacked core competitiveness and has not formed a coordinated industrial chain. There is a fracture phenomenon between the upper, mid, and lower streams, which leads to the inability of the entire industry to carry out sustainable development.

\section{Methodology}

Michael E. Porter believed that the vigorous development of industries mainly lies in the promotion of core competitiveness, and industries that lack competitiveness are naturally at a disadvantage in the development process [40]. Sustainable development serves as the primary focus of the industrial development strategy. Be it a traditional manufacturing industry, high and new technology industry, or a cultural and creative industry, only the constant enhancement of core competitiveness can ensure sustainable development in the future. The enhancement of core competitiveness serves as a driving force for sustainable development, while sustainable development, in turn, spurs enterprises to go further to enhance their core competitiveness; thus, the relationship between them is necessarily interactive [41]. Therefore, to realize sustainable development, China's animation industry shall improve its industrial chain and enhance its core competitiveness, thus, creating a healthy competitive environment and a model for cycle development. The Michael Porter Diamond Model was proposed to analyze the development of industries from the perspective of industrial competitiveness, which makes it more suitable for application to studies on sustainable development. Moreover, the model conducts dynamic analyses of industries based on multiple factors and plays a role in predicting and guiding practice [42], which makes it suitable for application to this study. Accordingly, based on the Michael Porter Diamond Model and literature review, this study put forward the sustainable development strategies of China's animation industry from the aspects of production factors, demand conditions, industrial chain, enterprise strategy within the industry, cultural factors, and policies. The Diamond theory was put forward by Professor Michael Porter of Harvard Business School. He deemed that the development of industry must be discussed from four environmental factors: production factors, demand conditions, related and supporting industries, and enterprise strategy. In addition, opportunities and the government play an important auxiliary role [40].

Among them, production factors refer to the performance of production in specific industry competition, such as human factors, natural factors, knowledge factors, capital factors, and other basic production conditions [40]. The animation industry mainly includes capital, talents, and technology; capital belongs to capital factors, talents to human factors, and technology to knowledge factors, which are the foundation of sustainable development for the industry. 
Demand condition refers to the market demand for products provided by the industry [40], which is the key driver of industrial development and the ultimate goal affecting the sustainable development of the industry.

Related and supporting industries are the upstream and downstream industries in the industrial chain, and improving the industrial chain can effectively promote the sustainable development of the industry.

Enterprise strategy refers to the organization, establishment, and management of enterprises in the industry [40], as well as the healthy competition and win-win cooperation among enterprises in the industry.

Government and opportunity come from outside the industry and have a macro auxiliary effect on the sustainable development of the industry. The opportunities for industrial development will change with the changes in government policies. Macro-control can promote the marketization process of the animation industry, and the government can also provide a social environment for the sustainable development of the industry [40]. Therefore, these two factors complement each other and are discussed as the same aspect in this study.

In this study, the Diamond Model was adjusted according to the characteristics of the animation industry. The animation industry is an important part of cultural and creative industries, and culture is the internal driving force for the development of the animation industry. Therefore, this study added cultural factors to the Diamond Model and combined government and opportunity as auxiliary factors to create a new Diamond Model as the theoretical basis of this study.

\section{Sustainable Development Strategy of the Chinese Animation Industry Based on the Diamond Theory}

\subsection{Production Factors}

\subsubsection{Funds}

The production factors in the animation industry mainly include capital, talents, and technology, among which capital is the most direct driving force to support development. As a creative industry with high investment, the animation industry needs huge financial support in terms of creation, distribution, and derivative development, and the financial situation of any link will affect the operation of the entire industrial chain. At present, China's animation industry is facing the problem of a shortage of funds. The industrial chain with animation as the core belongs to the linear chain development mode. As the demand for investment is high and the capital recovery period is long, few enterprises can afford the corresponding investment [43]. The lag of a capital investment operation system has led many animation brands to stop capital investment before entering the marketing and derivative development stages, which limits the production and investment of animation products. Therefore, constructing a capital investment guarantee system and setting up a professional financing guarantee institution for the animation industry have become the primary development strategy of the capital operation system of China's animation industry at present. China's animation enterprises are mainly small and mediumsized enterprises, and policy support and protection are more suitable for the current animation industry to carry out financing operations under the mechanism of market regulation. Moreover, efforts should be made to expand the channels of capital investment, with government support as the main part, private capital as the auxiliary part [44], and the introduction of foreign capital support. On this basis, it is necessary to carry out joint financing in the overall form of the industrial chain to improve the efficiency of capital investment.

\subsubsection{Talents}

The key indicator of expertise is the ability to produce an animation, which requires finance as well as talent [45]. People are the body and soul of the animation industry. As an intelligence-intensive and labor-intensive industry [46], the animation industry must be 
promoted by people's creativity. Whether it is technological progress, market promotion, or company management, talents are the key factors for the development of the animation industry. China's animation industry is generally facing the situation of talent shortage, especially the lack of senior compound talents, which shows that there are still some defects in the mode and content of animation talent training. The animation industry is a creative industry and places great emphasis on practice. The educational mode of college education, which emphasizes painting production while neglecting cultural creation, has led to a surplus of production talents, which makes it easier for students to become "workers" of foreign OEM online machinery, inhibits the original development and production of the entire industry, and results in an imbalance in the talent structure of the animation industry. When facing imported animation competition, the shortage of domestic animation talents directly leads to the disadvantage of domestic animation products, and the lack of original works hinders the sustainable development of the animation industry. The training mode of Chinese animation talents mainly depends on universities and colleges. Regarding the re-training mode of professional technical schools and enterprises, the existing reserve of compound talents cannot meet the needs of the rapid development of the animation industry in terms of the total number of compound talents, talent echelon composition, or related professional quality; therefore, it is necessary to identify demands for talent training. Schools and enterprises should cooperate to formulate teaching plans for production, teaching, and research, and cultivating innovative compound talents is the current development strategy for talents in the animation industry. The increased collaboration between the university and the industry is very important in the driving of innovations [47]. Therefore, schools and enterprises should formulate a systematic training mode, grasp the trend of talent demands, adjust the talent training structure, and reposition talent training according to the actual industrial situation. Taking Britain as an example, the main course materials of the animation and painting major in the University of the Arts London are prepared by experts in the industry; thus, the courses reflect the needs of the current industry to the greatest extent [48]. Therefore, China's schools and enterprises should also adopt the combined training mechanisms of production, education, and research to avoid the separation of schools and the industry and narrow the talent demand gap between schools and enterprises. At the same time, preferential policies can be formulated to attract high-end animation talents and management talents, strengthen the exchange and cooperation of animation talents at home and abroad, and improve the composition of the talent echelon.

\subsubsection{Technology}

The development of technology also has stimulated the growth of the animation industry [45]. The animation industry is a technology-intensive industry, technology provides the means and way to realize animation works, and the progress of technology plays a supporting role in the development of the animation industry [49]. In terms of production technology, the hardware and software of China's animation industry are highly dependent on foreign technologies, meaning both animation production equipment and related software, such as production and storage, are monopolized by technologically developed countries, and such dependence can hardly be reduced in the short-term [50]. Therefore, enterprises should cooperate with research institutions, carry out independent research and development based on actual needs, and strive for early realization of further scientific research and innovation in order to reduce dependence on foreign technologies.

Although independent innovation cannot be immediately realized in production technology at present, Chinese animation can still develop in technical content. Chinese culture provides a steady stream of formal support for the animation industry; for example, ink painting, paper cutting, shadow play, drama, puppets, and other forms of expression can be displayed with the existing technology. Chinese animation can adjust its existing technical means to use software and hardware, realize the production of original animation works with Chinese characteristics, and enhance the core competitiveness of Chinese animation. 


\subsection{Demand Conditions}

With the developments of the society and improved consumption ability, people's demand for cultural products is increasing day by day. As a vital part of cultural and creative industries, animation has naturally become an industry with high consumption willingness. In China, the scale of pan-two dimensions users has grown rapidly, reaching 350 million in 2018, among which the scale of online animation users has reached 219 million; thus, behind this huge scale of users is a huge demand market [51]. There are two main consumer groups in the animation market, children and young people. However, it is generally believed in China that animation is only suitable for children and is not suitable for adults to watch; thus, the industry caters to the aesthetic standards of children, meaning it has a single orientation for consumer groups [52]. Regardless of the production level or content of the works, it does not meet the consumption needs of adults and often misses huge market demands. Therefore, for China's animation industry, repositioning consumer groups to meet the needs of different groups of consumers is the primary task for the sustainable development of the animation industry.

The demand direction of the animation industry is divided into content demand and derivative demand. In terms of content demand, the industry needs to conduct a new survey and positioning of consumer groups, classify and evaluate consumer groups, create animation works suitable for different consumer groups, and carry out targeted marketing strategies according to consumer characteristics [53]. In terms of derivative demands, at present, the targeted children do not have the ability to spend; domestic derivatives are viewed as a minor hobby market consisting of relatively low prices, which is not attractive to adult consumers. Therefore, various derivatives should be developed according to the consumption ability and habits of different consumer groups, and the joint development of light hobbies and core hobbies should be adopted to meet the consumption needs of different ages and consumption levels.

\subsection{Related and Supporting Industries}

This factor refers to the upstream and downstream links in the industrial chain. A complete industrial chain is the core of sustainable development in the animation industry. The animation industrial chain is considered to be the chain with the widest scope and longest continuity in cultural industries [54], and mutual cooperation and support of all links can make the animation industry flourish [55]. The animation industry in developed countries presents a sustainable industrial cycle chain of animation productiondistribution-derivative development-income-reproduction [56] (Figure 3). However, as far as the current Chinese animation industry is concerned, the poor effectiveness of the industrial cluster and the incomplete industrial chain has led to many works not being able to effectively start the required follow-up operations, which affects the extension and virtuous circle of the animation industrial chain. The internal faults and disconnection have led to gaps in the management links and insufficient stamina for industrial upgrading, which has become the crux of the lagging market development.

Taking Disney as an example, a great deal of time was invested in planning and market research in the early stage, and relevant planning for the development of derivatives was completed; thus, the entire production process of animation works created a perfect industrial chain [57]. From the front end of the industrial chain, China's animation industry has not paid enough attention to market research, planning, or marketing. While the mid-processing links are relatively developed, many of them are OEM for foreign countries [46], and the development of downstream derivatives is insufficient. There is also a lack of well-known animation brands in the industry, which makes it difficult to form the brand effect. Moreover, the interoperability in the industrial chain is poor and lacks a sound base, the industry is dominated by small and medium-sized enterprises, and the strength of these enterprises is poor. As each link fights alone, the industrial production mode is not realized, which restricts the overall development of the industry. In the animation industry chain, the development and sales of derivatives are the most 
important way to promote the return of funds within the industry to give feedback to the contents. Whether the commercial return and reinvestment of the animation industry can be realized depends to a large extent on the development of derivatives downstream of the animation industry and the subsequent value links [58]. Therefore, the development of derivatives in the downstream of the industrial chain is particularly important. At present, the domestic derivatives development scale is small, the type is single, and quality control is not strict; at the same time, there is no reasonable copyright protection. Pirated goods affect the normal order of the derivatives market and hinder the process of animation industrialization [59]. Therefore, perfecting the animation industry chain, attaching importance to the development of upstream and downstream industries, balancing the proportion of industries, promoting the protection of intellectual property rights, opening up new markets for animation through the internet, and realizing industrial innovation have become the main development strategies of the animation industry chain.

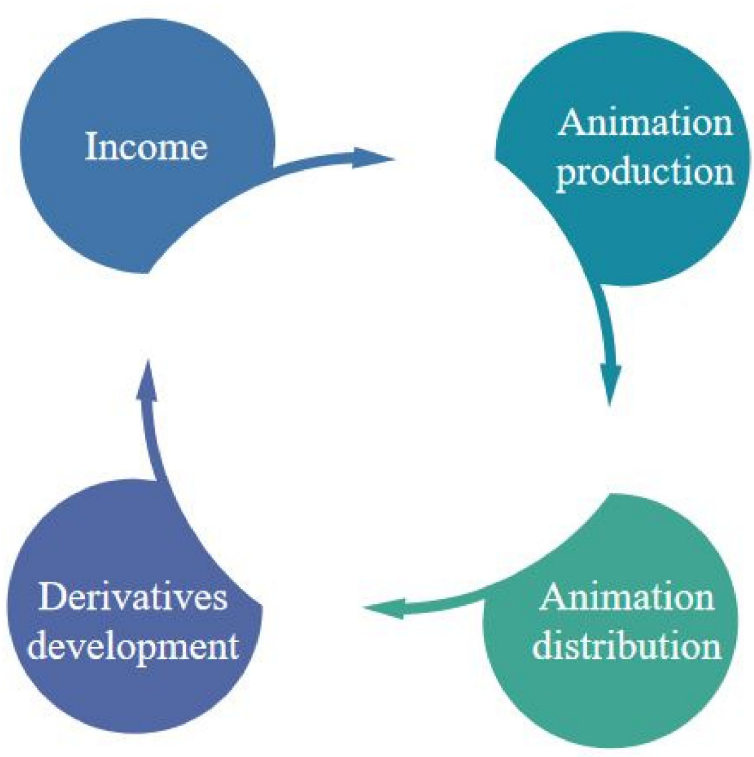

Figure 3. Circular Chain of the Animation Industry [56].

The perfection of the industrial chain first requires upstream works and downstream products to interact with each other. The development and sales of the works themselves and derivative products are all based on animation creations, with the works as the cornerstone, and good product development and marketing can effectively promote the creation of works [60]. As the first link in the industrial chain, animation creation is an important basic link; without excellent works, there is no successful product concept. Therefore, the first step to improve the industrial chain is to conduct appropriate preliminary research, take originality as a breakthrough, and create excellent works based on market demand. In downstream derivative development, it is necessary to promote the authorization of animated images and protect the intellectual property rights of the animation industry. China's animation industry has long been plagued by piracy, which makes some small and medium-sized enterprises afraid to invest in derivatives. Although the state has successively issued relevant laws and regulations to combat piracy, it is not enough to rely solely on national policy protection. Enterprises also need to raise protection awareness and establish effective anti-counterfeiting measures to reduce the harm of pirated products to enterprises. At the same time, the development of derivatives should be popular and pertinent. Popularization lies in the fact that the authorization of animated images can involve different fields. As different animation types have different derivatives, it is appropriate to formulate corresponding development plans according to different market targets; thus, animations cannot be generalized. 
The animation industry needs to improve relevant industrial policies, address the inherent faults of the industrial management system, and improve the animation industry chain through cross-border integration, including horizontal cross-domain promotions and vertical industry extensions [50]. In this process, the government has played the role of macro-control, taken the lead in strengthening awareness of intellectual property protection in society, and establishing laws and regulations to maintain a healthy development environment for the animation industry, while simultaneously increasing full-time personnel to ensure the implementation of its policies. Enterprises are the main participants and need to improve their originality, determine their position and role in the industrial chain, strengthen cooperation with other enterprises in the industrial chain, maintain good communication, enhance legal awareness, and protect their brand rights and interests. Practitioners are the executors of value activities and should focus on cultivating students' professional skills and professional qualities during school, understand the latest technologies and creative concepts at home and abroad, and strengthen the awareness of brand protection of works. Consumers are the terminal and final judge of the value of the industrial chain. The operation and development of the industrial chain are essential to meet the needs of consumers. Therefore, consumers also need to strengthen their awareness of copyright protection, support genuine animation, and encourage excellent animation works to occupy the market.

\subsection{Enterprise Strategy}

Michael E. Porter believed that successful industries must first go through the struggle of the domestic market to force them to improve and innovate [40] and then enter the international market after realizing a model of sustainable development. At present, China's animation enterprises are mainly small and medium-sized enterprises, which have a low and scattered capital scale and lack the scale effect. Although there are also large- and medium-sized enterprises recognized by the state, such as Alpha and Zoland, there is still a clear gap, as compared with foreign countries. Regarding enterprises, they do not have clear positioning or development focus and fail to build themselves into all-around enterprises. Moreover, large- and medium-sized enterprises tend to imitate others, lack their own cultural advantages, and can hardly form a unique symbol [43]. Small- and medium-sized enterprises often pursue profits in the early stage and ignore long-term planning. Due to a lack of funds, small and medium-sized enterprises have to turn to contract manufacturing for large-scale animations at home and abroad and have no time to create independently. Similarly, due to financial constraints, it is impossible to employ high-level management personnel for systematic planning, and they lack human resources management, which results in poor stability for enterprise personnel and high turnover costs. In the long term, it is difficult for the entire production team to stabilize; thus, they lack tacit understanding and identity. The animation industry is a technology-supported and market-oriented industry. However, the decision-makers of most animation enterprises are first engaged in animation creation, such as Sanchen Cartoons and Hongmeng Cartoons, thus, while they undoubtedly have the certain creative ability in animation art and technology, they often have shortcomings in management strategies, and there is a lack of professional management talents in enterprises, which results in an unreasonable talent structure and difficulties in forming market-oriented enterprise goals.

Therefore, animation enterprises with different scales and different development stages should adopt different development strategies. In the initial stage, small-scale enterprises should engage in market segmentation to build their own core competitiveness, while enterprises with a certain scale in the rising stage should integrate the upstream and downstream cooperative relationship [48] and build a win-win cooperative structure within the entire industrial chain, in order to obtain the corresponding market share. At the same time, the management modes of specialized production, large-scale operations, and collectivization operations should be carried out to promote the integration and centralized development of the animation industry. In the aspect of branding, corporate brands and 
animation brands should help each other, pay attention to the connotations of corporate culture, and enhance the spiritual feeling while emphasizing the appreciation of animated products to meet the spiritual needs of consumers and build a global corporate brand such as Disney.

Efforts should be made to improve the corporate types in the industrial chain, carry out the specialized division of labor according to different links of the animation industry, improve the composition of enterprises in each link, and promote the sustainable development of enterprises through improved management and technology [61]. Smalland medium-sized enterprises may adopt the mode of internal training and selection to enhance the stability of employees, establish a sound financial system and employ professional financial personnel, and rely on policies and themselves to form a good credit system to improve the success rate of their bank loans. As creativity is the carrier of the animation industry, small- and medium-sized enterprises need to continuously promote the construction of innovation mechanisms, improve their innovation ability, and promote the development, transformation, and upgrading of their enterprises.

\subsection{Cultural Factors}

As a vital part of cultural and creative industries, the core of the animation industry is "culture is king and creativity is soul". A country and its customs, society, and people can be reflected through animation [62]. The main creators of industrial clusters should have cultural consciousness and self-confidence, draw creative inspiration from traditional culture, and carry out creative transformation in the cultural context of the new era. Therefore, we can see that, in the field of animation, enduring excellent works not only retain the tradition of Chinese values in the expression of internal culture it also shows the modernity of mainstream values in modern life [63].

Cultural self-confidence is the foundation for the development of the animation industry. Although the special effects of pictures and the modeling of characters can attract the attention of the audience, what really touches people's hearts is the cultural connotations contained in the story. At present, Chinese animation generally shows its shortcomings through a lack of traditional spirit, imitation, and plagiarism. According to our final analysis, the lack of in-depth understanding of local culture leads to a cultural lack of confidence; therefore, Chinese animation creators need to take root in the local culture, establish the identity of cultural subjects, take the local aesthetic habits as the guide, avoid imitative creations, and prevent the invasion of foreign cultures [64]. Chinese traditional culture, daily life, ideology, and the social system are completely different and independent from typical western society. While China's long accumulated history provides rich materials for the early creativity of the animation industry, many domestic materials have not been adopted by domestic animation works but have been misappropriated by foreign countries. Foreign creators cannot deeply understand the connotations of Chinese culture and are utilitarian in the process of using Chinese cultural symbols; therefore, cultural discounts will appear in the process of creating works.

Colin Hoskins and R. Mirus [65] pointed out that cultural products in the international market are not recognized or understood by audiences in other regions due to cultural background differences, which leads to the reduction of their value. This phenomenon is called cultural discount. Specifically, cultural discount refers to the loss and reduction in the value of cultural products in the context of cross-culture and cross-region [66]. The main reason for this is the cultural value differences among consumers in different regions and cultures [67]. The United States is the most representative in the use of Chinese elements in animation, and both Mulan and Kung Fu Panda have misread and distorted Chinese culture. However, due to their mature creative process and artistic style, misread Chinese culture is still popular all over the world, which increases the misunderstanding of Chinese culture in other countries.

The cultural and creative attributes of the animation industry are destined to have great influence and publicity effect on social development and shoulder the social respon- 
sibility of promoting Chinese culture; therefore, greater attention should be paid to the cultural meaning expressed in the works. Taking Disney in the United States as an example, its industrial chain takes creative content as the center, and creative cultural content drives the manufacturing industry of cultural products, which then affects the sales industry of cultural products. On this basis, cultural and creative industries are integrated with other industries to form expanded cultural and creative industries, namely the multimedia industry, cultural tourism, and theme parks [68] (Figure 4). As an immigrant country, the United States has a culture different from that of other countries. In addition to its own cultural characteristics, it is inclusive; thus, it often uses other countries' cultural elements during creation and integrates its ideology on other countries' cultural elements, which can attract audiences from different countries, while also conveying its own cultural values, which promotes interaction between the animation industry and culture and realizes the common sustainable development of both.

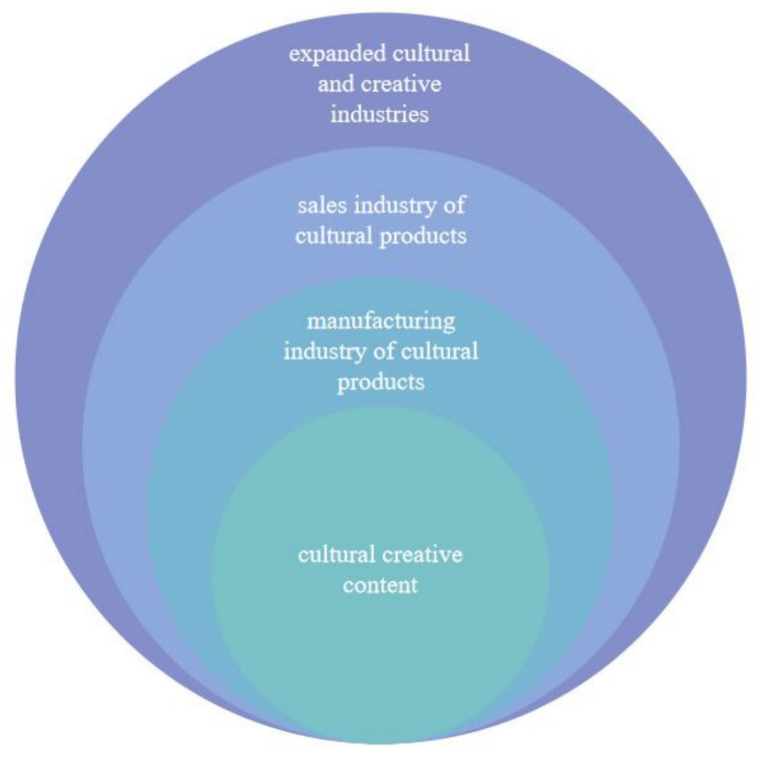

Figure 4. Industrial Chain Development Model of Disney [68].

It can be seen that cultural resources can enhance the recognition of consumer groups. The more animation products created with cultural creativity as the center can arouse the interest of consumer groups, the greater the development potential for the animation industry. In the current Chinese animation industry, the lack of cultural connotation is a common problem in Chinese animation creation, meaning the works lack creativity and cultural heritage, and the artistry and ideological content are insufficient. After all, the animation art form is only the carrier of cultural spirit, while cultural connotations endow animation with vitality if it only has external characteristics and traditional stories, is not cultural display [69]. Therefore, if Chinese animation wants to form its own style and realize the sustainable development of the industry, it is necessary to truly understand the traditional culture. The cognition of the traditional culture cannot stop at the superficial level. On the basis of cognition, in order to convey the spirit of the local culture in an interesting form, decode audiences' internal psychological structure, and change from external nationality to internal nationality, the various aspects of traditional culture should be transformed into vivid stories and animated images.

The animation industry is characterized by "open innovation" [70]; the success of the innovation depends on the excellent cultural content. From the perspective of early creativity, it is necessary to integrate and innovate excellent national cultural resources. The culture accumulated from China's long history provides rich materials for animation creation, and the myths, legends, and allusions are the source of practitioners' creation; thus, a deep understanding of national cultural heritage is the foundation of animation 
creation. While conducting in-depth research of local culture, we should also inherit and innovate our excellent culture, combine modern cultural elements to make the content fit the times, conform to the modern thinking mode of the people, and use global languages to tell Chinese stories, which tend to be implicit and full of metaphors. Therefore, obscure content should be avoided in the creation, and cultural discounts should be reduced as much as possible in cross-cultural communication to improve the acceptance of Chinese animation globally. Moreover, we should absorb a more excellent foreign experience, as globalization has intensified cultural exchanges between countries. Faced with its own rich cultural resources, China's animation industry has failed to transform itself into fruitful cultural achievements. The United States has carried out American-style transformation on the basis of Chinese cultural elements and created excellent works, such as Kung Fu Panda, which are also widely praised in China. Such cultural translation and integration are aspects that Chinese animation industry creators should consider and learn from.

\subsection{Government}

The government and opportunities play an auxiliary role in the sustainable development model of the whole animation industry, and the formulation of national policies will have a decisive impact on the formation and development of the industry. In addition, the sustainable development of the industry also urges the government to formulate policies to support it to a certain extent [71], and changes in government policies can provide new opportunities for industrial development; thus, this study combined the two auxiliary factors of government and opportunities into one.

In the past decade, China has issued a series of policies to support the animation industry from the aspects of support and reward, fiscal revenue, hardware support, personnel training, etc. [72] (Table 2). However, the existing policy subjects are scattered, and the communication of opinions among various departments is ineffective. At the same time, the policy content is vague, and vague words, such as "appropriate", "strive for", and "can" often appear [73], which increases the difficulty of implementing the policy at the grass-roots level, and the scope of policy benefits is limited. Most such policies focus on animation bases and large enterprises but care little about the vast majority of smalland medium-sized enterprises.

Table 2. Relevant Policies of China's Animation Industry in Recent Ten Years (Part) [72].

\begin{tabular}{|c|c|c|}
\hline Time & Issuing Body & Policy Name \\
\hline 2011 & $\begin{array}{l}\text { Ministry of Culture, Ministry of Finance, } \\
\text { State Taxation Administration, and } \\
\text { General Administration of Customs }\end{array}$ & $\begin{array}{l}\text { Interim Provisions of Animation Enterprises on Exemption from Import Tax } \\
\text { on Animation Development and Production Articles Imported by } \\
\text { Animation Enterprises }\end{array}$ \\
\hline 2012 & Ministry of Culture & $\begin{array}{l}\text { National Animation Industry Development Plan during the Twelfth } \\
\text { Five-Year Plan Period }\end{array}$ \\
\hline 2013 & $\begin{array}{l}\text { National Radio and } \\
\text { Television Administration }\end{array}$ & Nine Measures to Promote the Development of Domestic Animation Films \\
\hline 2014 & Council of State & $\begin{array}{c}\text { Some Opinions on Promoting the Integration and Development of Cultural } \\
\text { Creativity and Design Service Related Industries }\end{array}$ \\
\hline 2015 & Council of State & $\begin{array}{l}\text { Opinions on Several Policies and Measures to Vigorously Promote Mass } \\
\text { Entrepreneurship and Innovation }\end{array}$ \\
\hline 2017 & Ministry of Culture & $\begin{array}{l}\text { Cultural Industry Development Plan during the Thirteenth Five-Year } \\
\text { Plan Period }\end{array}$ \\
\hline 2019 & $\begin{array}{l}\text { National Radio and } \\
\text { Television Administration }\end{array}$ & $\begin{array}{c}\text { Opinions on Promoting the High-quality Development of Radio, Television, } \\
\text { and Network Audio-visual Industry }\end{array}$ \\
\hline
\end{tabular}

In light of the actual situation of the animation industry at this stage, the government should simultaneously play the macro-control role of supervision and support. Under strict standard supervision, financial support, and comprehensive and systematic guidance of the 
government's industrial development, the development ideas and goals of the animation industry should be clearly defined to create a good and relaxed industrial environment. Therefore, this study holds that the government should give comprehensive support to the animation industry from the two aspects of industrial policy and legal system in order that the animation industry can achieve a sustainable development model.

\subsubsection{Industrial Policy}

Industrial policy is the sum of the various policies of the government's intervention in the formation and development of industries to achieve certain economic and social goals [74], and a catalyst to promote the output of the industry and accelerate the adjustment of the industrial structure, thus, it has important practical and policy significance for the sustainable development of industries [75]. The policies regarding the animation industry can be divided into four aspects: positioning policy, constructive policy, normative policy, and incentive policy [48].

Positioning policies can express the government's attitude towards the animation industry, as well as its planning for the future development direction, which has an important impact on the development of the industry. Although such policies do not propose specific measures for the development of the industry, they play a strategic and directional fundamental role in the sustainable development of the entire industry [48]. At present, the government needs to clarify the specific position of the animation industry within the overall cultural and creative industry, as well as its significance to cultural development and the national economy, and raise its development to the national strategic level, as based on its value to the ideological development of young people and the dissemination of national cultural soft power.

Constructive policy specific to the animation industry is necessary to establish an investment and financing mechanism first, as the development of the animation industry cannot be separated from substantial financial support. Currently, a virtuous capital cycle cannot be formed within the industrial chain; therefore, it is necessary for the government to integrate resources across regions in a diversified manner, enhance the circulation of funds in the industrial chain, and promote the development of the animation industry by setting up special funds for it, guaranteeing loans, and reducing and exempting corporate taxes [48], in order to stimulate consumption and create demand. At the same time, measures should be taken to realize policy shifts, take the market as the leading factor, actively expand overseas markets, expand international cooperation, and enhance the international vision of local animation works.

The standardized management of the animation industry should start with a specialized division of labor in enterprises with different processes, scales, and business layouts in each link of the industrial chain and manage and support different types of enterprises in a targeted manner. In addition, the classification system of animation should be improved, and the animation market should be classified and regulated through various channels, such as industry self-discipline, and government or public supervision [76], in a bid to provide suitable animated works for consumers of different ages and types and promote the healthy and orderly development of the animation industry.

Incentive policies mainly lie in encouraging and stimulating the sustainable development of the industry, such as setting animation awards, subsidies, and other incentives to stimulate practitioners' creative enthusiasm. At present, China has paid increased attention to setting animation awards, carried out animation festival activities in various locations, subsidized and rewarded the winning works, and enhanced the enthusiasm of creators. In terms of subsidy support, the government should make scientific and reasonable decisions, and when giving special subsidies, it should strictly control the false self-claims of high quantity in the industry. The focus of subsidies should be to guide enterprises to improve product quality and form a reasonable business layout and industrial development structure. In terms of taxation, reasonable preferential policies should be formulated according to the current situation of the industry, and the types of funds made available in the in- 
dustrial chain should be improved. Reasonable incentive policies will greatly promote the development of the animation industry.

\subsubsection{Legal System}

The perfection of the legal system mainly lies in the protection of intellectual property rights. Intellectual property is the core of animation industry operation, and the frequent occurrence of piracy and infringement will seriously hinder the development of the animation industry. Therefore, all countries have spared no effort to protect intellectual property rights; for example, the protection period of the Mickey Mouse image, which was created in 1928 in the United States, should have expired in 2003; however, in 1998, the United States amended the Copyright Law to extend the protection period of the image by 20 years, and Mickey Mouse remains protected to date [77], thus, protecting the rights and interests of the Disney Group.

The animation industry has a unique industrial chain. The overall industrial chain can be said to focus on the formation, development, protection, appreciation, and transformation of intellectual property rights and builds sustainable industrial chains through the value transmission of intellectual property rights [78]. The intellectual property rights of the animation industry are the main source of profits in the animation industry. It can be reported in the form of design characters or films with the aim of not being reproduced by anyone other than the creators themselves [79]. The proliferation of piracy and infringement has not only seriously damaged the relevant interests of animation enterprises it also affects the enthusiasm of creators; therefore, it is necessary to protect animation intellectual property rights through coercive means.

At the source of protecting intellectual property rights, the government should first popularize publicity and education, improve the legal awareness of creators, establish the consciousness of protecting their intellectual property rights, encourage creators to register copyrights and trademarks of their works, and defend their legitimate rights and interests by law when their rights and interests are infringed. At the policy level, it is necessary to formulate a comprehensive legal system, clarify the scope of protection, severely crackdown on piracy and infringement, establish relevant legal advisory service platforms, improve legal aid channels, and protect the rights and interests of creators under the three-pronged approach of the legal system, law enforcement management system, and administrative management system, in order to optimize the development environment of the animation industry.

\section{Conclusions}

As an important part of cultural and creative industries, the animation industry covers many aspects, such as art, science and technology, culture, media, commerce, etc. The animation industry has become a pillar industry in many countries. The keywords of the animation industry include green, culture, and knowledge economy, and it is known as a "sunrise industry" in the 21st century. With the increasing emphasis on the animation industry in China, its sustainable development has become the main topic; however, there are always some obstacles and challenges in the development path of the "healthy, virtuous circular, and sustainable" "green" animation industry. Therefore, based on the Diamond Theory, this study analyzed the current Chinese animation industry from all aspects of the model and put forward strategies to promote the sustainable development of the Chinese animation industry.

This study found that capital is the direct force to promote the development of the animation industry, talents are the subject and soul of the sustainable development of the animation industry, and technology is the support for the sustainable development of the animation industry. The huge market demand provides a strong thrust for the development of the animation industry, a perfect industrial chain is a foundation for the sustainable development of the animation industry, a mature enterprise strategy can guarantee development, culture is the internal driving force for the development of the animation industry, and the government plays a leading role in the sustainable development of the animation industry. 
If the animation industry attempts to complete the process of sustainable development, it needs the joint efforts of all parts, which cannot be completed in a single aspect, as all links complement each other, support each other, and coordinated development is the best way for the animation industry to move towards sustainable development. Only with a healthy industrial environment, diversified talent structure, sufficient financial support, and perfect industrial chain can more high-quality enterprises grow and develop, form a fair and benign competition mechanism, and create more excellent animation works. When creating, we should deeply cultivate traditional culture, carry forward the connotations of Chinese culture, and form unique core competitiveness to attract a wider demand market and promote the promotion of national cultural soft power while improving economic benefits.

Of course, China's animation industry will encounter new opportunities and challenges in the process of sustainable development beyond the aspects mentioned in this study, meaning research on the sustainable development of the animation industry must be continuously deepened and improved, and its specific implementation measures and roles must be repeatedly verified through actual cases. This study intends to provide the theoretical and methodological basis and reference for the follow-up research by itself and others and jointly promotes the sustainable development model of the Chinese animation industry.

Author Contributions: Conceptualization: T.-T.F.; methodology: K.-K.F. and T.-T.F.; writingoriginal draft preparation: T.-T.F.; writing—review and editing: T.-T.F.; supervision: K.-K.F. All authors have read and agreed to the published version of the manuscript.

Funding: This research was funded by the Taiwan Ministry of Science and Technology, grant number 109WFA2610235.

Institutional Review Board Statement: Not applicable.

Informed Consent Statement: Not applicable.

Data Availability Statement: Not applicable.

Acknowledgments: We would like to express our gratitude to the Taiwan Ministry of Science and Technology for providing research resources on this study.

Conflicts of Interest: The authors declare no conflict of interest.

\section{References}

1. Liu, B. Research on the Policy and Innovation of China's Animation Industry; Communication University of China Press: Beijing, China, 2016; p. 6.

2. Peng, L. Animation as a Creative Industry; China Eastern Press: Shanghai, China, 2009.

3. Napier Susan, J. Anime from Akira to Princess Mononoke: Experiencing Contemporary Japanese Animation; Palgrave: New York, NY, USA, 2001.

4. Bilton, C. Management and Creativity: From Creative Industrie to Creative Management; New World: Beijing, China, 2010.

5. Richard, E.; Caves, R.E. Economics of Creative Industries-The Commercial Way of Art; Xinhua Books: Beijing, China, 2004.

6. Niracharapa, T. Competitiveness of Animation Industry: The Case of Thailan. World Acad. Sci. Eng. Technol. 2007, 8, 2265-2270.

7. Prospective Industry Research Institute. Analysis of the Development Status and Trend of China's Animation Industry in 2020. The Total Output Value of China's Animation Industry Reached RMB194.1 Billion in 2019. 2020. Available online: https:/ / www.qianzhan. com/analyst/detail/220/200228-0ea5b576.html (accessed on 26 March 2021).

8. Lo, Y.C.; Zhang, C.; Tseng, C.F.; Chiang, Y.T.; Fu, M.T. A Study on the Development Predicament of China's Animation and Corresponding Strategies. Mark. Wkly. 2020, 2, 63-64.

9. Kuo, H. The Animation Industry in China Should Seek Sustainable Development. Academics 2008, 6, 149-153.

10. Sha, J. Research on the Development Process and Future Prospects of Chinese Animation Industry. Commun. Power Res. 2020, 23, 48-49.

11. Lee, C.L. Viewing the Development of Animation in China from the Development Course of Animation. Art Educ. Res. 2019, 15, 104-105.

12. Sangwook, K. Developments and prospects of animation industry in China. China Sinol 2012, 16, 125-156.

13. National Radio and Television Administration. Several Opinions on the Development of China's Film and Television Animation Industry. 2004. Available online: http:/ / www.cntv.cn/program/dhc/20040531/101617.shtml (accessed on 26 March 2021). 
14. General Office of the State Council. The Several Opinions on Promoting the Development of China's Animation Industry. 2006. Available online: https:/ / baike.baidu.com/item/\%E5\%85\%B3\%E4\%BA\%8E\%E6\%8E\%A8\%E5\%8A\%A8\%E6\%88\%91\%E5\%9 B\%BD $\%$ E5\%8A \%A $\%$ E6\%BC\%AB\%E4\%BA\%A7\%E4\%B8\%9A\%E5\%8F\%91\%E5\%B1\%95\%E7\%9A\%84\%E8\%8B\%A5\%E5\%B9 $\%$ B2 $\%$ E6\%84\%8F\%E8\%A7\%81/2381537?fr=aladdin (accessed on 26 March 2021).

15. Chu, F. (Ed.) The General Administration of Press, Publication, Radio, Film and Television Introduced Measures to Encourage the Development of Domestic Cartoons; China News Network, 2013. Available online: http://www.chinanews.com/gn/2013/0 7-17/5054812.shtml (accessed on 26 March 2021).

16. Lu, B.; Cheng, Y.M.; Niu, X.Z. Annual Report on Development of China's Animation Industry; Social Sciences Academic Press: Beijing, China, 2011.

17. Tien, L. Media Competitiveness Evaluation; Peking University Press: Beijing, China, 2012.

18. Liu, Y. The Development of the Animation Industry and the Enhancement of the National Cultural Soft Power. J. Southwest Minzu Univ. 2010, 5, 223-228.

19. Wei, C.F. Study on the Problems faced by Chinese Animation Based on the Status Quo of Shanghai Animation Industry. Media 2008, 3, 24-26.

20. Hernández, Á.D.H. The Anime Industry, Networks of Participation, and Environments for the Management of Content in Japan. Arts 2018, 7, 42. [CrossRef]

21. Japanese Economy Division. Japan Animation Industry Trends. Japan Economic Monthly, 2005. Available online: https: //www.jetro.go.jp/en/reports/market/pdf/2005_35_r.pdf (accessed on 2 June 2021).

22. Yusuf, S.; Nabeshima, K. Postindustrial East Asian Cities: Innovation for Growth; World Bank and Stanford University Press: Washington, DC, USA, 2006.

23. Wasko, J.M. The Development of the Korean Animation Industry-Historical Economic, and Cultural Perspectives; California State University: Long Beach, CA, USA, 1980.

24. Morisawa, T. Managing the unmanageable: Emotional labour and creative hierarchy in the Japanese animation industry. Ethnography 2014, 16, 262-284. [CrossRef]

25. Zhao, Y.H. Marketing of Animation Derivatives; China Machine Press: Beijing, China, 2012.

26. Lee, P. Studies on Policies of China's Animation Industry. Master's Thesis, Changchun University of Technology, Changchun, China, 2012.

27. Chiu, S.B.; Yu, W.Y. Inspiration and Reference from the Development of Animation Industry in Japan and South Korea. J. Hebei Norm. Univ. Sci. Technol. 2012, 11, 113-118.

28. Tsai, A.N.; Tsao, L. Reflection on the Development of China's Animation Industry. World Reg. Stud. 2009, 18, 129-134.

29. Textbook Office of Ministry of Human Resources and Social Security. Introduction to Animation; China Labor and Social Security Publishing House: Beijing, China, 2009.

30. Pan, R.F. Research and Practice of Animation Industry Model; China Radio and Television Publishing House: Beijing, China, 2010.

31. Yin, C.; Tan, L. (Eds.) Animation Industry; Sichuan University Press: Chengdu, China, 2009.

32. Li, F. The Pan-aesthetic Evolution of Images in the Motif and Resources of the Legend of Nezha. J. Chin. Cult. 2020, 3, 95-103, 158

33. Li, C.Y. Research on the Nationality of Chinese Animation-Based on the Perspective of Traditional Culture Expression; Communication University of China Press: Beijing, China, 2011.

34. Garmann Johnsen, I.H. Formal Project Organization and Informal Social Networks: Regional Advantages in the Emergent Animation Industry in Oslo, Norway. Eur. Plan. Stud. 2011, 19, 1165-1181. [CrossRef]

35. Chang, L.L. "IP+" Development Path of Animated Films in the Era of "Internet+". New Media Res. 2020, $22,42-44$.

36. Ma, C. Research on Internet Marketing Strategy of Domestic Animation Films. Master's Thesis, Nanjing University of the Arts, Nanjing, China, 2016; p. 16.

37. Yoon, H. Globalization of the animation industry: Multi-scalar linkages of six animation production centers. Int. J. Cult. Policy 2015, 23, 634-651. [CrossRef]

38. Tschang, T.; Goldstein, A. Production and Political Economy in the Animation Industry: Why Insourcing and Outsourcing Occur. In Proceedings of the Research Collection Lee Kong Chian School Of Business, DRUID Summer Conference, Elsinore, Denmark, 14-16 June 2004.

39. Zhou, Z. On the Present Situation and Prospect of China's Animation Film Derivative Industry Chain from the Marketing of Domestic Animation Blockbusters. Arts Rev. 2019, 192, 90-102.

40. Porter, M.E. National Competitive Advantages; CITIC Press: Beijing, China, 2012.

41. Zhou, C. Study on Sustainable Development of Construction Enterprises based on core competitiveness. Ph.D. Thesis, Wuhan University of Technology, Wuhan, China, 2009.

42. Tung, Y. Comparative Analysis of Comparative Advantage Theory and Competitive Advantage Theory. Master's Thesis, Jilin University, Changchun, China, 2004.

43. Huang, M.M. Research on the Development Model of Chinese Animation Industry Based on Diamond Theory. News Commun. 2016, 7, 4-8.

44. Kamarudin, H.S.; Sajilan, S. Critical Success Factors of Technopreneurship in the Creative Industries: A Study of Animation Ventures. Rev. Integr. Bus. Econ. Res. 2013, 1, 1-37. 
45. Yoon, H.; Malecki, E.J. Cartoon planet: Worlds of production and global production networks in the animation industry. Ind. Corp. Chang. 2010, 19, 239-271. [CrossRef]

46. Westcott, T. An overview of the global animation industry. Creat. Ind. J. 2011, 3, 253-259. [CrossRef]

47. Suwannatat, P.; Anuntvoranich, P.; Chandrachai, A. University and animation industry collaboration: New product development process. Int. J. Humanit. Soc. Sci. 2012, 2, 106-114.

48. Yang, C. Research on the Competitiveness of Chinese Animation Industry Based Upon the Diamond Theory. Ph.D. Thesis, Dalian Maritime University, Dalian, China, 2014.

49. Ma, H.P. Research on Innovation and Development of Animation Industry in China. Guangxi Soc. Sci. 2015, 6, $203-207$.

50. Chan, H.C. Analysis of International Competitiveness of Chinese Animation Industry. J. Liaoning Tech. Univ. 2013, 15, 479-484.

51. Peng, W. Research on the Path of Enhancing the International Competitiveness of China's Animation Industry from the Perspective of Cultural Confidence. Master's Thesis, Shijiazhuang Tiedao University, Shijianzhuang, China, 2019.

52. Zhiu, S.C. Present Situation and Countermeasures of Chinese Animation Market. West. Radio Telev. 2016, $10,126$.

53. Kao, P. Development and design of animation derivatives based on users' perceptual needs. Fash. Color 2019, $12,43-44$.

54. Zhao, C.H. Northeast China Cartoon Industry Development Present Situation and Promotion Strategy. J. Northeast. Norm. Univ. 2011, 6, 53-58.

55. Heydari, J.; Chaharsooghi, S.K.; Alipour, L. Animation supply chain modelling and diagnosis: A case study in animation industry of Iran. Int. J. Bus. Perform. Supply Chain. Model. 2009, 1, 319-332. [CrossRef]

56. Tsao, Y. The Significance of the Development of Animation Derivative Products. Lit. Life Wenhai Art Gard. $2014,6,142$.

57. Tseng, C. Resource Integration Strategy and Design Performance in Disney Animation Planning. Decoration 2018, 3, $128-129$.

58. Christopheerson, S.; Storper, M. The City as Studio; The word a back Lot: The Impact of Vertical Disintegration on the Location of the Motion Picture Industry. Environ. Plan. D Soc. Space 1986, 4, 305-320. [CrossRef]

59. Wang, C.C. On the Development of Animation Derivative Products. China Publ. 2009, 6, $22-25$.

60. Wang, Y. Creative Development of Chinese Animation Industry-Based on the Two-Way Investigation of Artistic Creation and Market Operation. Ph.D. Thesis, Zhejiang University, Hangzhou, China, 2015.

61. Zhang, Y.M. Research on the Development Countermeasures of Chinese Animation Industry Cluster from the Perspective of Industrial Cluster Competitiveness. Master's Thesis, Northeastern University, Shenyang, China, 2013.

62. Islam, M.B.; Samshuddin, A.K.; Choudhury, M.R. Prospects and Challenges of the Animation Industry in Bangladesh. Int. J. Comput. Graph. Animat. 2013, 3, 13-20. [CrossRef]

63. Zhao, H.B. On the Development Dilemma of Chinese Contemporary Animation from the Perspective of Culture. Master's Thesis, Nanjing University of Aeronautics and Astronautics, Nanjing, China, 2013.

64. Zhang, C. Critical Research on Chinese Animation in the New Historical Context. Ph.D. Thesis, Northwest University, Xian, China, 2018; p. 41.

65. Hoskins, C. Global Television and Film: An Introduction to Industrial Economics; Xinhua Books: Beijing, China, 2004.

66. Walls, W.D.; McKenzie, J. The Changing Role of Hollywood in the Global Movie Market. J. Media Econ. 2012, 25, 198-219. [CrossRef]

67. Sousa, C.M.; Bradley, F. Cultural Distance and Psychic Distance: Two Peas in a Pod? J. Int. Mark. 2006, 14, 49-70. [CrossRef]

68. Lin, M.L. Disney Enlightenment of Cultural Core to Chinese Animation Film Industry. J. Beijing Film. Acad. 2013, 5, 80-84.

69. Yuan, C.L. Perplexity under the Slogan-Reflection on the Nationalization of Chinese Animation. Times Lit. First Half Month 2010, $5,244-245$.

70. Van Egeraat, C.; O'Riain, S.; Kerr, A. Social and Spatial Structures of Innovation in the Irish Animation Industry. Eur. Plan. Stud. 2013, 21, 1437-1455. [CrossRef]

71. Chin, H.C. Industrial Economics Research of Chinese Cartoon; China Market Press: Beijing, China, 2006.

72. Prospective Industry Research Institute. 2020 Chinese Animation Industry Market Analysis: The Market Scale is Nearly 200 Billion, Capital Market Investment is Becoming More Rational. 2020. Available online: https://bg.qianzhan.com/trends/detail/ 506/200402-163c5b88.html (accessed on 6 April 2021).

73. Zhang, H.C. Research on Cultural Industry Creativity: Mechanism, Guarantee Mechanism and Incentive Policy. Ph.D. Thesis, Huazhong Normal University, Wuhan, China, 2014.

74. Chen, S.C. Glossary of Symmetric Economics (18). Takungpao, 2016. Available online: http://finance.takungpao.com/mjzl/ mjhz/2016-11/3391506.html (accessed on 6 April 2021).

75. Li, W.C.; Cheng, M.N. Substantive Innovation or Strategic Innovation? -The Impact of Macro-industrial Policies on Microenterprise Innovation. Econ. Res. J. 2016, 4, 60-73.

76. Hao, R.R. Chinese Animation Grading is Imperative. Publ. Wide-Angle 2014, 9, 10-11.

77. Chen, P. (Ed.) Luster of Classic Mickey Gone? Bus. China 2020, 1, 126-129.

78. Liu, C.Y. On the Sustainable Development of Cultural Industry. Guang Ming Daily, 6 June 2012; 11th Edition.

79. Limano, F. Sustainability Indonesia animation intellectual property (Study case Youtube channel). In Proceedings of the IOP Conference Series: Earth and Environmental Science, Volume 729, International Conference on Biospheric Harmony Advanced Research (ICOBAR 2020), Jakarta, Indonesia, 23-24 June 2020. 